\title{
NILAI PENDIDIKAN KARAKTER RELIGIUS DAN CINTA TANAH AIR NOVEL RANTU 1 MUARA KARYA AHMAD FUADI
}

\author{
Rahmat Gunawan \\ Universitas Sebelas Maret \\ Jl. Ir. Sutami No.36A, Jebres, Kota Surakarta, Jawa Tengah 57126 \\ E-mail: rahmatg02@gmail.com \\ Suyitno \\ Universitas Sebelas Maret \\ Jl. Ir. Sutami No.36A, Jebres, Kota Surakarta, Jawa Tengah 57126 \\ E-mail: yitsuyitno52@gmail.com \\ Slamet Supriyadi \\ Universitas Sebelas Maret \\ Jl. Ir. Sutami No.36A, Jebres, Kota Surakarta, Jawa Tengah 57126 \\ E-mail:pripus.lppmuns@yahoo.co.id
}

\begin{tabular}{c|c|c}
\hline Received: & Revised: & Approved: \\
18/10/2018 & $23 / 11 / 2018$ & $23 / 11 / 2018$ \\
\hline
\end{tabular}

DOI: http:/ / dx.doi.org/10.32332/akademika.v23i2.1238

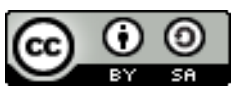

Nilai Pendidikan Karakter Religius dan Cinta Tanah Air Novel Rantu 1

Muara Karya Ahmad Fuadi Licensed Under a Creative Commons AttributionShareAlike 4.0 International License

\begin{abstract}
This research aims to describe religious character education values and love for the homeland in the novel of Rantau 1 Muara written by Ahmad Fuadi. The mentioned novel clearly tells about the value of of struggle, persistence, obedience to God and the
\end{abstract}


life view that aims to achieve success with an Arabic incantation stating that man saara ala darbi washala, that means who keep going on his path will surely achieve his goals. The method used in this study is a descriptive qualitative method. The novel of Rantau 1 Muara by Ahmad Fuadi, written in 2013,, is used as a source of data with a total of 395 pages. The data in this research cover the story units in form of dialogs, paragraphs, and tables that show the value of religious character education. the data collection techniques used in this research are note taking and literature study. the steps followed in analyzing the novel are by interpreting it using the already existing theories and then describing it in accordance with the research objectives. Based on the research results, there are 17 frequencies containing within them the religious existence of human relations to God such as worshiping, greeting, praying, giving thanks and asking forgiveness. The religious existences among human and human are asking for protection, obeying parents, intimacy, and praying for others. Furthermore, the religious existence of human with nature is praising the beauty of nature. While in the value of loving the homeland character education, there are 3 frequencies including the manifestation of the value of patriotism in relation to one's self, namely the sense of nationalism and the sense of tolerance between religious communities.

Keywords: Character, Novel, and Education.

\begin{abstract}
Abstrak
Penelitian ini bertujuan untuk mendekripsikan nilai-nilai pendidikan karakter religius dalam novel Rantau 1 Muara karya Ahmad Fuadi. Novel Rantau 1 Muara merupakan novel yang mengisahkan tentang suatu nilai perjuangan, kegigihan, ketaatan terhadap Tuhan serta pandangan hidup yang bertujuan untuk mencapai suatu kesuksesan dengan sebuah mantera man saara ala darbi washala, yaitu siapa yang berjalan di jalannya akan sampai ke tujuan. Metode yang digunakan dalam penelitian ini adalah metode deskriptif kualitatif. Sumber data dalam penelitian ini adalah novel Rantau 1 Muara karya Ahmad Fuadi pada tahun 2013 dengan jumlah 395 halaman. Data penelitian mencakup tentang satuan cerita dalam dialog, paragraf, dan tabel yang menunjukan nilai pendidikan karakter religius. Teknik pengumpulan data dilakukan dengan teknik simak catat, dan studi pustaka. Langkah-langkah yang dilakukan dalam menganalisis novel tersebut dengan menginterpretasikan berdasarkan teori yang ada, kemudian dideskripsikan sesuai dengan tujuan penelitian. Hasil analisis data, diketahui terdapat 17 frekuensi yang terbagi di dalamnya meliputi, wujud religius hubungan manusia dengan Tuhan diantaranya, beribadah, mengucap salam, berdoa, bersyukur dan mohon ampun. Wujud religius manusia dengan manusia di antaranya meminta perlindungan, berbakti kepada orang tua, keakraban, dan
\end{abstract}


mendoakan orang lain. Selanjutnya, wujud religius manusia dengan alam yaitu memuji keindahan alam sedangkan nilai pendidikan karakter cinta tanah air terdapat 3 frekuensi meliputi wujud nilai cinta tanah air hubungannya dengan diri sendiri yaitu rasa nasionalis dan rasa toleransi antara umat beragama.

Kata Kunci: Karakter, Novel, dan Pendidikan.

\section{A. Pendahuluan}

Pendidikan karakter merupakan aset yang sangat penting dalam kehidupan setiap manusia, baik secara individual maupun kelompok. Setiap diri manusia berusaha untuk mendapatkan pendidikan yang layak dalam mencari ilmu pengetahuan. Pendidikan karakter pun sudah bukan menjadi hal yang tabu lagi dalam dunia pendidikan. Pendidikan yang baik dan terarah akan memberikan manfaat yang bermanfaat juga didalam kehidupan. Seorang anak harus dibekali dengan pendidikan karakter sejak dini, agar bisa ditekankan dalam kehidupan sosial untuk berperilaku baik serta menciptakan seorang yang berpendidikan, berkarakter, kreatif dan cerdas. Hal diharapkan pada pendidikan karakter yang dapat berkembang dengan mengaplikasikan nilai-nilai luhur dalam bangsa dan agama yang berorientasi mencintai tanah air dengan menekankan pendidikan agama.

Pembelajaran sastra di sekolah bertujuan agar peserta didik dapat menghayati serta mengapresiasi bentuk karya sastra seperti cerpen, novel, puisi, pantun. Karya sastra menjadi bacaan yang positif dan hiburan yang menyenangkan dalam pembacaan teks. Tidak jarang peserta didik merasa enggan untuk membaca novel di sekolah. Hal tersebut biasanya dipengaruhi oleh kurangnya minat dan minimnya bahan bacaan berupa novel. Effective teaching is pleasurable and richly repays the investment of time and energy that it requires. ${ }^{1}$ Menurut Khan, konsep pendidikan karakter dengan karakter cinta tanah air yaitu sikap pribadi, hasil proses kesadaran pemberdayaan cinta tanah air yang diarahkan untuk meningkatkan kualitas pendidikan. ${ }^{2}$ Menurut Nurfalah dan Kurniawati, salah satu alasan 2010).

${ }^{1}$ Khan, Yahya, Penilaian Pembelajaran Bahasa (Yogyakarta: BPFE - Yogyakarta,

${ }^{2}$ Khan, Yahya. 
pentingnya pendidikan karakter yaitu untuk mengembangkan suatu bangsa, maka diperlukan cinta tanah air dan agama. ${ }^{3}$

Terdapat suatu filosofi pada novel Rantau 1 Muara yang menyatakan bahwa hidup adalah perantauan, yang dimana pada suatu saat akan kembali ke akarnya yaitu ke muara. Muara manusia adalah menjadi hamba sekaligus khalifah di muka bumi ini. Tugas kita sebagai seorang hamba adalah mengabdi. Sebagai khalifah, tugas kita bermanfaat. Jadi, hidup adalah pengabdian dan kebermanfaatan". ${ }^{4}$ Dalam hal ini, kita diajarkan untuk memahami salah satu makna dalam novel ketiga dari Ahmad Fuadi yaitu Rantau 1 Muara ini dengan sebuah mantra "man saara ala darbi washala siapa yang berjalan dijalannya akan sampai ditujuan". 5 Novel Rantau 1 Muara memberitahukan betapa pentingnya merantau di negeri orang, berpetualang dengan mewujudkan tekad dan cita-cita, selain dapat melihat dunia, kita juga dapat mengeluarkan kita dari zona nyaman dan lebih mandiri dengan bertahan mencari ilmu di negeri orang. Bukan hanya tujuan kebahagiaan dan keberhasilan dunia tapi juga tujuan hakiki seperti cita-cita yang kita wujudkan dengan penuh usaha dan juga kegigihan. Jadi, membuat kita sadar bahwa kehidupan itu tidak kekal, dan sesukses apapun kita di dunia akan kembali dalam kehidupan yang abadi, apakah akan sukses juga di akhirat kelak tergantung bekal kita di dunia. Berdasarkan pemaparan di atas dalam pembelajaran pengajar harus membuat kreatif untuk menjadi bahan bacaan yang tepat untuk peserta didik di sekolah menengah pertama (SMA) yaitu novel Rantau 1 Muara karya Ahmad Fuadi, dipilih karena sangat cocok dan juga bacaan yang tidak sulit. Jadi novel Rantau 1 Muara ini terdapat niliai pedidikan karakter yang diajarkan dalam siswa SMA yang mendasar sebagai bahan bacaan sastra yang baik.

Ahmad Fuadi lahir di Sumatera Barat, tepatnya di daerah Bayur Maninjau tanggal 30 Desember 1973. Bekerja sebagai wartawan dan pekerja sosial mampu mengaplikasikan sebuah perjalanan hidup yang di tulis dalam novel. Novel Rantau 1 Muara karya Ahmad Fuadi dipilih

${ }^{3}$ Farida Nurfalah dan Indah Kurniawati, "Character Education Communication Model Nation to Form the Integrity of Self in Students," Journal of Humanities and Social Sciences (AHJSS) 3, no. 1 (2015): 151-62.

4 Fuadi, A., Rantau 1 Muara (Jakarta: Gramedia Pustaka Utama Gramedia Widiasarana Indonesia, 2013).

${ }^{5}$ Fuadi, A. 
menjadi objek kajian dalam penelitian disini karena mengandung nilai pendidikan karakter religius dan juga cinta tanah air menjadi salah satu faktor pendorong karakter untuk pembacanya. Karena di dalam isi bacaannya ringan mudah dipahami oleh pembaca, serta tingkat popularitas novel ini sangat tinggi. Ahmad Fuadi dijuluki seorang Scholarshiphunter yang mampu mendapatkan sembilan beasiswa sekaligus untuk dapat belajar di luar negeri. Di tahun 2004, ia mendapat beasiswa Chevening Award berkesempatan belajar di Royal Holloway, University of London. Dari keseluruhan ia telah berhasil mendapatkan kesempatan untuk belajar dan tinggal di negara Kanada, Singapura,, Amerika Serikat, Italia dan Inggris. Novel pertamanya yaitu Negeri Lima Menara, Ranah 3 Warna, Rantau 1 Muara, Berjalan Menemus Batas, Berjuang Ditanah Rantau, Rantau Satu Muara dan Anak Rantau. Dari pemaparan tersebut bisa menjadi penunjang bagi peserta didik untuk mencontoh perjalanan hidup Ahmad Fuadi yang berlatar belakang sebagai santri di pondok Madani, Gontor Jawa Timur yang mengaplikasikan dalam kehidupan, beberapa mantera sewaktu belajar di pondok dahulu yaitu : "man jadda wajada", siapa yang bersungguh-sungguh akan berhasil, "man shabara zafira" siapa yang bersabar akan beruntung, dan "man saara ala darbi washala" siapa yang berjalan dijalannya akan sampai ditujuan.

Oleh karena itu, tujuan dari artikel ini untuk mendeskripsikan nilai-nilai pendidikan karakter religius dan cinta tanah air dalam novel Rantau 1 Muara karya Ahmad Fuadi. Hal ini perlu dikaji oleh peneliti untuk menemukan nilai pendidikan karakter religius dan cinta tanah air pada novel Rantau 1 Muara, sehingga masyarakat dapat mengetahui pentingnya tujuan pendidikan karakter religius dan cinta tanah air tersebut.

Nilai pendidikan karakter yang terdapat pada novel Rantau 1 Muara yang nanti akan di bahas yaitu nilai religius dan cinta tanah air. Karena kedua nilai pendidikan karakter tersebut sangat cocok untuk diterapkan dalam pembelajaran siswa SMA, yang bertujuan dapat meniru dan mengambil contoh yang positif dalam pembelajaran. Karena hidup adalah pedoman yang berguna bagi nusa maupun bangsa. Penelian ini berharap dapat mengambil contoh yang di tuturkan dalam novel Rantau 1 Muara yang pertama Religius, meniru dan mengambil contoh positif yang dapat memacu keberanian menjalankan uhkuwah islam yang bagaimana berpegang teguh pada ajaran-ajaran Islam. Kedua nilai Cinta tanah air, 
untuk hal ini sangat penting sekali selain mengenal ajaran-ajaran islam, kita wajib menerapkan cinta tanah air agar kedua hal tersebut berjalan dengan imbang. Hal ini dikarenakan sejatinya dari hal tersebut kita menghargai para leluhur kita yang sudah berjuang memerdekakan negara kita Indonesia serta mendapatkan kesesuaian apa yang kita harapkan.

Pendidikan menurut John Dewey adalah proses pembentukan kecakapan fundamental secara intelektual dan emosional kearah alam dan sesame manusia. ${ }^{6}$ Tujuan pendidikan dalam hal ini agar generasi muda sebagai penerus generasi tua dapat menghayati, memahami, mengamalkan niali-nilai atau norma-norma tersebut dengan cara mewariskan segala pengalaman, pengetahuan, kemampuan dan keterampilan yang melatarbelakangi nilai-nilai dan norma-norma hidup dan kehidupan.

Pendidikan karakter adalah gerakan nasional untuk menanamkan nilai karakter baik yang membentuk kaum muda yang etis, bertanggung jawab, dan peduli dengan lingkungannya. ${ }^{7}$ Pendidikan karakter merupakan salah satu dari beberapa solusi untuk mengatasi masalah degradasi moral yang terjadi pada bangsa ini. Pengembangan Pendidikan budaya dan karakter yang terintegrasi dalam proses pembelajaran berupa pengenalan nilai melalui fasilitas yang didapat menyadari pentingnya nilai dalam kehidupan, dan nilai internalisssion ke dalam perilaku siswa setiap hari melalui proses belajar baik yang terjadidi dalam dan di luar kelas di semua mata pelajaran. ${ }^{8}$ Menurut Bohlin et. al, kata "karakter" diambil dari bahasa Yunani charassein, yang berarti menandai atau menuliskan. Seiring waktu maknanya telah berevolusi menjadi tanda atau tanda yang khas, dan dari situlah timbul konsep kita tentang karakter sebagai pola perilaku individu dan konstitusi moralnya. Karakter adalah kumpulan kompleks karakteristik psikologis yang memungkinkan seseorang bertindak sebagai agen moral. Dengan kata lain, karakternya bermacam-macam. Ini bersifat psikologis. Hal ini berkaitan dengan fungsi moral. ${ }^{9}$ Dalam anatomi moral

${ }^{6}$ Masnur Muslich, Pendidikan karakter: menjawab tantangan krisis multidimensional, Cet. 1 (Jakarta: Bumi Aksara, 2011).

7 Abourjilie, C, Character Education (North Carolina: Department of Public Instruction, 2002).

${ }^{8}$ Iyam Maryati dan Nanang Priatna, "Integration of Values Mathematics Characters through Contextual Learning (Literatur Study)," 4th ICRIEMS Proceedings Published by The Faculty Of Mathematics And Natural Sciences Yogyakarta State University, 2017, 41-49.

${ }^{9}$ Karen E. Bohlin dkk., Building character in schools resource guide, 1st ed, The JosseyBass education series (San Francisco: Jossey-Bass, 2001). 
penulis pertama, tujuh aspek psikologis karakter diidentifikasi: tindakan moral, nilai moral, kepribadian moral, emosi moral, penalaran moral, identitas moral, dan karakteristik dasar. ${ }^{10}$ Menurut Rusdiyah, pendidikan karakter adalah proyek pendidikan jangka panjang karena sesuai dengan makna origini-nya; karakter adalah proses mengukir nilai-nilai yang dianggap baik ke dalam hati siswa. ${ }^{11}$

Menurut Kemendiknas terdapat nilai pendidikan karakter yang terkandung dalam novel. ${ }^{12}$ Kajian penelitian pada artikel ini berdasarkan 18 nilai pendidikan karakter yang meliputi: nilai religius, jujur, toleransi, disiplin, kerja keras, kreatif, mandiri, demokratif, rasa ingin tahu, semangat kebangsaan, cinta tanah air, menghargai prestasi, bersahabat, cinta damai, gemar membaca, peduli lingkungan, peduli sosial, dan tanggung jawab. ${ }^{13}$ Berlandaskan pada fungsi pendidikan menurut Undang-Undang RI Nomor 20 Tahun 2003 tentang Sistem Pendidikan Nasional, yaitu mengembangkan kemampuan dan membangun watak serta peradaban bangsa yang bermartabat dalam rangka mencerdaskan kehidupan bangsa dan untuk mengembangkan potensi peserta didik agar menjadi manusia yang beriman dan bertakwa kepada Tuhan yang Maha Esa, berakhlak mulia, sehat, berilmu, cakap, kreatif, mandiri, dan menjadi warga negara yang demokratis serta bertanggung jawab.

Menurut Schaps dan Lewis mengkonseptualisasikan pendidikan karakter sebagai instruksi yang mencari pengembangan warga "peduli, berprinsip, dan bertanggung jawab. ${ }^{14}$ Pentingnya menumbuhkan pendidikan karakter di dalam diri agar kedepan menjadi lebih baik untuk mencapai suatu tujuan yang sempurna. Dari hal tersebut, unsur fundamental yang berakar pada nilai moral dari pendidikan itu sendiri

${ }^{10}$ Marvin W. Berkowitz dan John H. Grych, "Fostering Goodness: Teaching Parents to Facilitate Children's Moral Development," Journal of Moral Education 27, no. 3 (September 1998): 371-91, https://doi.org/10.1080/0305724980270307.

${ }^{11}$ Evi Fatimatur Rusydiyah, "Character Education Through the Constructivist Design of Islamic Education Subject at Elementary School Pembangunan Jaya II in Gedangan Sidoarjo," AL-Ta Lim 21, no. 3 (30 November 2014): 227-38, https://doi.org/10.15548/ jt.v21i3.108.

${ }^{12}$ Kemendiknas, Pengembangan Pendidikan Budaya dan Karakter Bangsa (Jakarta: Badan Penelitian dan Pengembangan Kurikulum, 2010).

${ }_{13}$ Agus Wibowo, Pendidikan karakter: strategi membangun karakter bangsa berperadaban, Cet. 1 (Yogyakarta: Pustaka Pelajar, 2012).

14 Schaps, E dan Lewis,C, "Perils on an essential journey: Building school community," Phi Delta Kappan 81, no. 3 (1999): 215-18. 
terlupakan. Akibatnya pendidikan hanya menghasilkan manusia yang skolastik dan pandai secara intelektual namun kurang memiliki karakter utuh sebagai pribadi, yang seharusnya pendidikan karakter dapat menjadi kunci kesuksesan bagi pengembangan diri setiap individu. ${ }^{15}$

Hal ini diperkuat dengan Permendikbud Nomor 23 Tahun 2015 Pasal 1 (2) tentang Penumbuhan Budi Pekerti, yaitu yang awalnya Penumbuhan Budi Pekerti dan selanjutnya disingkat menjadi PBP merupakan kegiatan pembiasaan sikap dan perilaku positif yang ada di sekolah yang dimulai sejak dari hari pertama sekolah, masa orientasi peserta didik baru untuk jenjang sekolah menengah pertama, sekolah menengah atas dan sekolah menengah kejuruan, sampai dengan kelulusan sekolah. Dari pendapat tersebut untuk itu pembelajaran yang berhubungan dengan kepribadian seseorang dan berorientasi pada pembentukan karakter peserta didik dapat diwujudkan melalui pengoptimalan pembelajaran sastra. Hal ini menjadi penting karena sastra dapat digunakan sebagai media yang strategis untuk meningkatkan mutu pendidikan karakter sekarang dan juga masa depan yang berguna bagi bangsa (Permendikbud, 2015).

Seseorang dapat dikatakan berkarakter atau berwatak dalam kehidupannya jika ia telah berhasil menyerap nilai dan keyakinan yang dikehendaki masyarakat serta nantinya akan dapat digunakan sebagai kekuatan moral dalam hidupnya dengan hasil yang kebermanfaatan untuk diri sendiri maupun orang lain. Jika seseorang sejak lahir sudah diarahkan dan dibekali dengan nilai pendidikan karakter, maka kedepannya seseorang tersebut akan dapat menempatkan dimana posisi yang baik dan buruk. Hal itu tentu sangat menjadi hal yang positif untuk dapat diterapkan dalam kehidupan sehari-hari dan juga dalam dunia pendidikan.

Menurut Lickona beberapa bentuk nilai pendidikan yang sebaiknya diajarkan yang ada disekolah adalah kejujuran, keadilan, toleransi, kebijaksanaan, disiplin diri, tolong menolong, peduli sesama, kerja sama, keberanian, dan sikap demokratis. Nilai pendidikan karakter tersebut berkaitan dengan pengetahuan moral (moral knowing), perasaan moral (moral felling), dan perilaku moral (moralbehavior). Berdasarkan ketiga komponen ini dapat dinyatakan bahwa karakter yang baik

${ }^{15}$ James C. Sarros, Brian K. Cooper, dan Anne M. Hartican, "Leadership and Character," Leadership E Organization Development Journal 27, no. 8 (Desember 2006): 682-99, https://doi.org/10.1108/01437730610709291. 
didukung oleh pengetahuan tentang kebaikan, keinginan untuk berbuat baik, dan melakukan perbuatan kebaikan. Ada beberapa komponen karakter baik diantaranya 1) Pengetahuan Moral meliputi: kesadaran moral, pengetahuan nilai moral, pengetahuan perspektif, pemikiran moral, pengambilan keputusan, pengetahuan pribadi. Selanjutnya (2) Perasaan Moral meliputi: hati nurani, harga diri, empati, mencintai hal yang baik, kendali diri, kerendahan hati. Dari dua paparan tersebut tercipta sebuah (3) Tindakan Moral meliputi: kompetensi, keinginan, dan kebiasaan. ${ }^{16}$

Pendidikan karakter merupakan salah satu dari beberapa solusi untuk mengatasi masalah degradasi moral yang terjadi pada bangsa ini. Pengembangan Pendidikan budaya dan karakter yang terintegrasi dalam proses pembelajaran berupa pengenalan nilai melalui fasilitas yang didapat menyadari pentingnya nilai dalam kehidupan, dan nilai internalisssion ke dalam perilaku siswa setiap hari melalui proses belajar baik yang terjadi di dalam dan di luar kelas di semua mata pelajaran. ${ }^{17}$ Pendidikan karakter sama tuanya dengan pendidikan itu sendiri. Manfaatnya turun sepanjang sejarah, pendidikan telah memiliki dua tujuan besar yaitu membantu orang menjadi cerdas dan membantu mereka menjadi baik. ${ }^{18}$ Karakter mempunyai hubungan yang berkonotasi 'positif' nilainya atau tidak netral. Dengan demikian, seseorang dengan karakter adalah orang yang memiliki kualitas moral positif tertentu. 'Kekuatan karakter' berhubungan langsung dengan kebajikan. ${ }^{19}$ sedangkan kekuatan karakter dilihat sebagai unsur psikologis yang menumbuhkan kebajikan. Salah satu kriteria utama karakter kekuatan adalah bahwa karakter tersebut berkontribusi besar untuk sepenuhnya mengaktualisasikan potensi seseorang dan cita-cita dalam membangun kehidupan yang baik, yang bermanfaat bagi diri sendiri dan orang lain. ${ }^{20}$

${ }^{16}$ Lickona, T, Educating for character. Mendidik untuk Membentuk Karakter.Terj. Juma Wadu Wamaungu (Jakarta: Bumi Aksara, 2016).

${ }_{17}$ Maryati dan Priatna, "Integration of Values Mathematics Characters through Contextual Learning (Literatur Study)."

18 Thomas Lickona, “The Return of Character Education" 51, no. 3 (1993): 6-11.

19 Kokom Komalasari dan Didin Saripudin, "The Influence of Living Values Education-Based Civic Education Textbook on Student's Character Formation," International Journal of Instruction 11, no. 1 (25 Januari 2018): 395-410, https://doi.org/10.12973/ iji.2018.11127a.

20 Philips, Simon, Refleksi Karakter Bangsa (Jakarta: Forum Kajian Antroplogi Indonesia, 2008); Christopher Peterson dan Martin E. P. Seligman, Character Strengths and Virtues: A Handbook and Classification (Washington, DC : New York: American Psychological 
Jika kita melihat pada karakter bangsa Indonesia didasarkan pada Pancasila sebagai fondasi bangsa dan visi hidup bangsa Indonesia. Karakter ini sesuai dengan nilai hidup, yaitu berbagai kebiasaan yang secara universal mendasari baik dan harmonis hubungan antara kita dan orang lain di sekitar kita. Nilai pribadi dan sosial mencakup perdamaian, penghargaan, cinta, tanggung jawab, kebahagiaan, kerja sama, kejujuran, kerendahan hati, toleransi, kerendahan hati, kebebasan dan persatuan. ${ }^{21}$ Karakter yang baik terdiri dari pengertian, kepedulian, dan bertindak berdasarkan inti nilai etika. ${ }^{22}$ Menurut Lickona Kemitraan Pendidikan Karakter (Character Education Partnership - CEP) telah mengidentifikasi 11 prinsip pendekatan komprehensif terhadap pendidikan karakter, diantaranya: promosikan nilai etika inti sebagai dasar karakter yang baik. Tentukan karakter secara komprehensif untuk memasukkan pemikiran, perasaan, dan perilaku. Gunakan pendekatan yang komprehensif, disengaja, proaktif, dan efektif. Buat komunitas sekolah yang peduli. Berikan siswa kesempatan untuk terlibat dalam tindakan moral. Berikan kurikulum yang bermakna dan menantang yang membantu semua siswa untuk sukses. Dorong motivasi intrinsik siswa untuk belajar dan menjadi orang baik. Libatkan staf sekolah sebagai profesional dalam komunitas pembelajaran dan moral. Dukung kepemimpinan moral bersama dan dukungan jangka panjang untuk pendidikan karakter. Melibatkan keluarga dan anggota masyarakat sebagai mitra dalam pendidikan karakter. Evaluasi karakter sekolah, stafnya, dan siswanya untuk menginformasikan upaya pendidikan karakter. ${ }^{23}$

Kemendiknas BPPPK berpendapat bahwa pendidikan budaya dan karakter bangsa dimaknai sebagai pendidikan yang mengembangkan nilainilai budaya dan karakter bangsa pada diri peserta didik sehingga mereka memiliki nilai dan karakter sebagai karakter dirinya, menerapkan nilainilai tersebut dalam kehidupan dirinya, sebagai anggota masyarakat, dan warga negara yang religius, nasionalis, produktif dan kreatif. ${ }^{24}$ Menurut

Association ; Oxford University Press, 2004).

21 Tillman, D, Living values: Avtivities for children ages 8-14 (Jakarta: PT Gramedia Widiasarana Indonesia, 2004).

22 Tom Lickona, Eric Schaps, dan Catherine Lewis, "Of Effective Character EducationTM," Character Education Partnership, 2002, 25-34.

${ }^{23}$ Lickona, T, Schaps, E, dan Lewis, C, CEP's Eleven Principles of Effective Character Education (Washington, DC: Character Education Partnership, 2003).

${ }^{24}$ Kemendiknas, Pengembangan Pendidikan Budaya dan Karakter Bangsa. 
Lickona pendidikan karakter yang efektif membutuhkan pendekatan yang bersifat proaktif, komprehensif, dan harus intensif. ${ }^{25}$

Menurut Sunarti, karakter merupakan istilah yang menunjuk kepada aplikasi nilai-nilai kebaikan dalam bentuk tingkah laku. ${ }^{26}$ Walaupun istilah karakter dapat menunjuk kepada karakter baik atau karakter buruk, namun dalam aplikasinya orang dikatakan berkarakter jika mengaplikasikan nilai-nilai kebaikan dalam perilakunya. Jika kita melihat pendidikan karakter merupakan sebuah usaha yang disengaja untuk dikembangkan kebajikan yang memungkinkan kita memimpin pemenuhan hidup dan membangun dunia yang lebih baik. ${ }^{27}$

Pendidikan karakter dipandang sebagai bagian dari pendidikan kewarganegaraan dalam kurikulum hal itu dikemukakan menurut Revell. ${ }^{28}$ Selanjutnya menurut Healea Oleh karena itu membentuk karakter anak harus dimulai sedini mungkin bahkan sejak anak itu dilahirkan. ${ }^{29}$ Pendidikan bertujuan untuk memberi para siswa kompas moral internal untuk mengenali yang baik, menginginkan apabaik dan melakukan apa yang baik.

Pendidikan karakter, selain tumbuh melalui karakter lebih berakar pada nilai-nilai agama dan norma-norma hidup bersama, bisa juga dilakukan melalui berbagai kegiatan berdasarkan kecintaan pada lingkungan dan ke tanah air. sebuah pandangan dari banyak solusi itu dapat dilakukan, antara lain pertama, penanaman karakter. Formula ini telah didorong oleh pemerintah, bahkan melalui regulasi, meski tetap tidak memadai. Yang kedua adalah pertumbuhan tanah air cinta-diri. Salah satu bentuk yang dimiliki manusia karakter adalah sikap nasionalisme menjadi lebih tinggi karena itu menunjukkan diri mereka memiliki kemampuan menjalankan agama dan nasional nilai-nilai. Terakhir, yang ketiga adalah pertumbuhan sikap inklusif di Indonesia perbedaan. Menunjukkan rasa

\footnotetext{
${ }^{25}$ Lickona, T, Educating for character (New York, NY: Bantam Books, 1991).

${ }^{26}$ Sunarti, Euis, Menggali Kekuatan Cerita (Jakarta: PT Elek Media Komputindo, 2005).

${ }^{27}$ Lickona, T, Educating for character.

${ }^{28}$ Lynn Revell dan James Arthur, "Character Education in Schools and the Education of Teachers," Journal of Moral Education 36, no. 1 (Maret 2007): 79-92, https:/ / doi. org/10.1080/03057240701194738.

${ }^{29}$ Christopher Daryl Healea, "Character Education with Resident Assistants: A Model for Developing Character on College Campuses," Journal of Education 186, no. 1 (Januari 2006): 65-77, https://doi.org/10.1177/002205740618600107.
} 
hormat, simpati dan aktif terlibat dalam keragaman adalah bentuk sikap etis yang penting dalam pendidikan karakter pendidikan. ${ }^{30}$

Salah satu cara untuk menanamkan sikap cinta tanah air yaitu dengan memberikan praktek tersebut di kelas. Guru pun saat mengimplementasikan pendidikan karakter perlu memiliki kecerdasan yang dapat mengajak siswa untuk masuk kedalam pembelajaran pendidikan karakter relijius dan cinta tanah air. ${ }^{31}$ Fokus lebih lanjut (dan konsekuen) kepentingan dari literatur internasional berhubungan dengan protagonis pendidikan karakter: para guru (asosiasi dengan guru dan mengajar). Dalam hal ini, pengalaman guru agama, persepsi dan pemikiran tentang pendidikan karakter ${ }^{32}$, tanggung jawab untuk menjadi model peran $^{33}$ dan rasa keberhasilan ${ }^{34}$ diselidiki, serta pendidikan mereka dan cara mempersiapkan guru untuk menjadi pendidik karakter ${ }^{35}$. Dari perspektif yang lebih pedagogis, artikel juga melihat metode dan strategi pengajaran dalam agama. ${ }^{36}$

${ }^{30}$ Segara, I Nyoman Yoga, "Character Education trough Disposition Growth, Love of the Homeand and Inclusive Life Attitude," Dharma Acarya Faculty International Seminar (DAFIS) 1 (2016): 24-31.

${ }^{31}$ Rafika Bayu Kusumandari Istyarini, "Character Education Development ModelBased E-Learning and Multiple in Telegency in Childhood in Central Java," Global Journal of Computer Science and Technology: H Information \& Technology 15, no. 3 (2015): 12.

32 Beachum, F, "Pre-service Teachers' Perceptions of Character Education," MidWestern Educational Researcher 18, no. 4 (2005): 45-50; Romanowski, M. H, “Through the Eyes of Teachers: High School Teachers' Experiences with Character Education," American Secondary Education 34, no. 1 (2005): 6-23; Beachum, F. D dkk., "Support and importance of character education: pre-service teacher perceptions," Education 133, no. 4 (2013): 470-80.

${ }_{33}$ Wouter Sanderse, "The Meaning of Role Modelling in Moral and Character Education," Journal of Moral Education 42, no. 1 (Maret 2013): 28-42, https:/ / doi.org/10.108 0/03057240.2012.690727.

34 Demirel, M, "Self-efficacy beliefs of elementary teachers and school principals for character education," Hacettepe University Journal of Education 37 (2009): 36-49; Alice T Ledford, "Professional Development for Character Education: An Evaluation of Teachers' Sense of Efficacy for Character Education," Scholar-Practitioner Quarterly 5, no. 3 (t.t.): 25673.

${ }^{35}$ Nucci, L dkk., "Preparing preservice teachers for character education in urban elementary schools," Journal of Research in Character Education 3, no. 81-96 (2005); Revell dan Arthur, "Character Education in Schools and the Education of Teachers"; Lapsley, D. K. dan Narvaez, D, "Character Education. In K. A. Renninger \& I. E. Sigel (Eds), Handbook of Child Psychology," Child Psychology in Practice 4 (2006): 248-96.

${ }^{36}$ Diana Brannon, "Character Education: It's a Joint Responsibility," Kappa Delta Pi Record 44, no. 2 (Januari 2008): 62-65, https://doi.org/10.1080/00228958.2008.1051649 6; Helen R. Stiff-Williams, "Widening the Lens to Teach Character Education Alongside Standards Curriculum," The Clearing House: A Journal of Educational Strategies, Issues and Ideas 83, no. 4 (24 Mei 2010): 115-20, https:/ / doi.org/10.1080/00098651003653030. 


\section{B. Metode Penelitian}

Adapun objek dalam penelitian ini adalah karya sastra berupa novel yang berjudul Rantau 1 Muara karya Ahmad Fuadi terbitan pertama tahun 2013. Novel ini merupakan sebuah novel yang di dalamnya mengandung nilai-nilai pendidikan karakter religius. Novel ini mengajarkan tentang sebuah semangat perjuangan, serta pandangan hidup dalam sebuah harapan. Novel ini terdiri dari 395 halaman yang diterbitkan oleh penerbit Gramedia Pustaka Utama. Penelitian ini menggunakan metode deskriptif kualitatif. Metode ini digunakan untuk mendeskripsikan data tertulis dalam novel Rantau 1 Muara karya Ahmad Fuadi yang di dalamnya terdapat nilai pendidikan karakter religius yang terjalin dalam tokoh Alif dalam masa perantauannya sebagai tempat berkarya, pencarian belahan jiwa dan juga pencarian dimana hidup akan bermuara.

Data yang terdapat dalam kajian ini mencakup tentang satuan cerita dalam dialog, paragraf, dan tabel yang menunjukan nilai pendidikan karakter religius dalam novel Rantau 1 Muara. Teknik pengumpulan data dilakukan dengan teknik simak, catat, dan pustaka. Teknik ini dilakukan dengan membaca novel secara erulang-ulang agar mendapatkan data yang akurat Sugiyono. ${ }^{37}$ Teknik analisis data dilakukan dengan cara mrnginterpretasikan data, membaca keseluruhan data, menganalisis lebih detail, menerapkan proses koding untuk di deskripsikan, menyajikan kembali dalam narasi, dan menginterpretasikan atau memaknai data. ${ }^{38}$

\section{Hasil Penelitian dan Pembahasan}

Novel Rantau 1 Muara adalah novel yang mengajarkan kita tentang sebuah perjuangan dan mengajarkan tentang semangat perjuangan, nilai moral, cinta kasih, kekerabatan, tanggung jawab, pandangan hidup, serta sebuah harapan. Novel Rantau 1 Muara ini dideskripsikan dengan mengambil cerita dari sebuah pengalaman pribadi penulisnya dalam pencarian tempat berkarya, pencarian belahan jiwa dan juga pencarian dimana hidup akan bermuara. Dengan latar cerita di kota Jakarta, Washington DC yang merupakan kota impian penulis, dan kembali bermuara pada tanah

${ }^{37}$ Sugiyono, Metode Penelitian Pendidikan Pendekatan Kuantitatif, Kualitatif, dan RED (Bandung: Alfabeta, 2014).

38 Creswel, J. W, Research design: pendekatan kualitatif, kuantitatif, dan mixed (Yogyakarta: PT Pustaka Pelajar, 2010). 
air Indonesia di (Jakarta). Pada saat itu sosok Alif yang merasa berdiri di pucuk dunia, dia telah mengelilingi sebagian dunia, tulisan-tulisan yang dibuatnya sudah tersebar di berbagai media, dan dia menjadi lulusan dengan nilai terbaik. Dengan penuh harapan nantinya akan ada banyak perusahaan yang merekrutnya, namun pada saat itu dirinya lulus pada masa yang tidak tepat yaitu pada saat reformasi yang banyak perusahaan menolak surat lamarannya. Alif mulai bimbang, namun dengan secercah harapan ketika dirinya menjadi seorang wartawan di majalah terkenal saat itu, dia jatuh cinta kepada gadis yang dahulu pernah dicurigainya. Di kota Jakarta terciptalah sebuah harapan baru, Alif mendapatkan beasiswa ke Washington DC, dan saat Alif tinggal di Amerika, dirinya memiliki teman dan pekerjaan yang baik, dengan berkehidupan yang mencukupi dengan tujuan untuk membantu adik-adiknya dan juga Amak tercapai juga. Sampai dirinya menyaksikan sebuah peristiwa pada tanggal 11 september 2001 di gedung World Trade Center di kota New York, dan orang terdekat Alif menghilang dari peristiwa tersebut.

Oleh karena itu, dirinya harus memikirkan misi hidupnya kembali akan kemanakah tujuannya. Dengan memiliki mantera sewaktu mondok dahulu "man saara ala darbi washala" (siapa yang berjalan di jalannya akan sampai tujuan) yakni menuju kepada sang khaliq. Berpetualang dengan mewujudkan tekad dan cita-cita, selain dapat melihat dunia, kita juga dapat berkarya, mengeluarkan kita dari zona nyaman dan lebih mandiri dengan bertahan mencari ilmu di negeri orang. Dengan merantau kita bisa mendapatkan apa yang kita inginkan dalam mimpi yang harus kita raih dalam cita-cita. Bukan hanya tujuan kebahagiaan dan keberhasilan dunia tetapi juga tujuan hakiki seperti cita-cita yang kita wujudkan dengan penuh usaha dan juga kegigihan. Jadi, membuat kita sadar bahwa kehidupan itu tidak kekal, dan sesukses apapun kita di dunia akan kembali dalam kehidupan yang abadi, apakah akan sukses juga di akhirat kelak tergantung bekal kita di dunia. Berawal dari sebuah perjalanan peencarian misi hidup yang pada hakikatnya adalah sebuah perantauan. Jadi novel Rantau 1 Muara menceritakan tentang sebuah konsistensi dalam menuju tujuan, pencarian belahan jiwa, menemukan tempat bermuara, muara dari segala muara. 
Berikut ini adalah hasil penelitian nilai-nilai pendidikan karakter pada novel Rantau 1 Muara karya Ahmad Fuadi, yang di dalamnya terdapat nilai pendidikan karakter religius yaitu:

\section{Religius}

Religius merupakan sebuah sikap serta perilaku yang patuh untuk menjalankan ajaran dalam agama serta dapat toleran kepada agama lain dalam menjalankan ibadah. Hidup bersama-sama saling menghargai, rukun dengan agama lainnya. Dalam karakter religius harus menjadi bekal oleh setiap orang dalam menghadapi setiap perubahan-perubahan zaman, agar nantinya dapat berprilaku baik serta terciptanya moral yang baik. Berikut merupakan contoh dari nilai religius yang terdapat dalam novel R1M adalah.

\section{a. Wujud nilai religius hubungan manusia dengan Tuhan. \\ 1) Beribadah}

Berikut ini adalah contoh kutipan yang termasuk ke dalam beribadah, hal tersebut dapat dibuktikan pada kutipan berikut: "Ramadan dan Idul Fitri datang ke DC dengan kemeriahan tersendiri. Kami berdua berusaha sering hadir di tarawih bersama di KBRI yang diimami Ustad Fariz, yang dikelola oleh Ikatan Muslim Indoneisa. Kalau tidak sempat berjalan ke KBRI yang cukup jauh, kami salat di musala kampus. Kadang kala, kami mencoba pula salat di Islamic Center Washington DC yang gagah di Embassy Row, Massachusetts Avenue". (hlm.361)

Pada kutipan di atas termasuk ke dalam hubungan beribadah manusia dan tuhannya, yaitu dengan ikut memeriahkan serta meramaikan kegiatan pada waktu bulan ramadan. Kami melakukan ibadah sholat dan tarawih bersama-sama dengan rekan yang lain, melakukan ibadah merupakan hal yang wajib untuk umat beragama, sebagai tanda patuh dan bakti manusia kepada Tuhannya. Kutipan lainnya yang termasuk ke dalam beribadah, hal tersebut dapat dibuktikan pada kutipan berikut. "Akhirnya kami sepakat untuk meminta petunjuk-Nya. "Cinta, kita salat Istikharah yuk. Dia selalu tahu apa yang paling baik buat kita," ajakku". (hlm.385)

Pada kutipan di atas termasuk dalam hubungan beribadah dari manusia kepada tuhannya. Saat fikiran dipenuhi kepayang dan juga kebingungan, maka pilihan yang tepat adalah meminta petunjuk dari 
Allah supaya diberikan kemudahan dan ditunjukan pilihan yang baik saat itu. Akhirnya Alif dan Dinara sepakat untuk melaksanakan salat istikharah berdua. Selalu percaya perbuatan yang baik dan ikhlas akan dibalas juga dengan hal yang baik.

2) Mengucap Salam

Berikut ini adalah contoh kutipan yang termasuk ke dalam mengucap salam, hal tersebut dapat dibuktikan pada kutipan berikut “Assalamualaikum, ketemu lagi kita,"sapaku iseng ke sisi kamar". (hlm.1)

Pada kutipan di atas tokoh Alif menunjukan bahwa termasuk nilai religius dengan mengucapkan salam saat masuk kamar yang sudah lama ditinggalkannya. Mengucapkan salam termasuk sebuah nilai religius yang harus di ajarkan dalam agama islam.

3) Berdoa

Berikut ini adalah contoh kutipan yang termasuk ke dalam berdoa, hal tersebut dapat dibuktikan pada kutipan berikut "Dengan memejamkan mata dan menyebut basmalah, aku lepas surat-surat lamaran itu terbang ke lusinan organisasi internasional dan korporasi". (hlm.18)

Pada kutipan di atas, menunjukan bahwa termasuk dalam nilai religius yang ditunjukan pada kutipan "Dengan memejamkan mata dan menyebut basmalah, aku lepas surat-surat lamaran itu terbang ke lusinan organisasi internasional dan korporasi". Kata-kata bismilah adalah termasuk dalam nilai religius yang biasanya diucapkan pada saat seseorang melakukan sesuatu yang berharap sebuah pengharapan yang berkah. Kutipan lainnya yang termasuk ke dalam berdoa, hal tersebut dapat dibuktikan pada kutipan berikut."Dengan pelupuk mata yang berat, aku bubungkan doaku terakhir sebelum tidur. Ya Tuhan, mudahkanlah jalanku menuntut ilmu ke negeri orang. Lalu aku telungkupkan buku TOEFL ke mukaku, siapa siapa tahu malam ini isi buku ini mencair dan mengalir pindah ke otakku". (hlm.156)

Pada kutipan di atas termasuk nilai religius, hal itu dibuktikan pada "aku bubungkan doaku terakhir sebelum tidur. Ya Tuhan, mudahkanlah jalanku menuntut ilmu ke negeri orang". Doa adalah permintaan seseorang kepada penciptanya (Allah) agar semua urusan yang telah dilakukannya mendapat kemudahan dan juga bisa sukses nantinya. 
4) Bersyukur

Berikut ini adalah contoh kutipan yang termasuk ke dalam bersyukur, hal tersebut dapat dibuktikan pada kutipan berikut "Alhamdulillah, do'a dan usaha itu memang selalu didengar-Nya". (hlm. 31)

Pada kutipan di atas menunjukan bahwa merupakan nilai religius, hal itu dibuktkan dengan kutipan "Alhamdulillah, do'a dan usaha itu memang selalu didengar-Nya". Allhamdulillah merupakan suatu ungkapan seseorang pada saat telah melakukan sesuatu atau lebih tepatnya bersyukur kepada Tuhan yang telah dikaruniai nikmatnya. Kutipan lainnya yang termasuk ke dalam bersyukur, hal tersebut dapat dibuktikan pada kutipan berikut. "Ingin aku melompat setinggi-tingginya dan berteriak lega sekeras-kerasnya. Impian besar itu tercapai jua akhirnya. Alhamdulillah, ya Tuhan janji-Mu memang tidak meleset, apa yang diperjuangkan dengan sepenuh hati dan raga, lambat laun akan sampai". (hlm.186)

Bersyukur atau berterima kasih ke-pada Tuhan Yang Maha Esa adalah sikap yang menghargai nikmat yang telah diberikan oleh Allah SWT kepada umatnya. Syukur berarti memfungsikan seluruh kenikmatan Allah pada tujuan yang sebenarnya. Bersyukur merupakan rasa nikmat atas segala karunia Allah SWT dengan mengucapkan Alhamdulillah sebagai rasa ungkapan syukur dan terima kasih kepada-Nya. Pada kutipan di atas, ucapan ber-syukur kembali diucapkan oleh tokoh dengan mengucapkan Alhamdulillah se-bagai ucapan terima kasih kepada Allah karena ia merasakan kebesaran Allah yang telah melihat kesungguhannya dan kerja kerasnya dalam meraih impian di sertai dengan pendekatan kepada Allah dengan menjalankan perintah-Nya dan menjauhi larangan-Nya.

5)

Mohon Ampun

Berikut ini adalah contoh kutipan yang termasuk ke dalam mohon ampun, hal tersebut dapat dibuktikan pada kutipan berikut. Dalam novel Rantau Satu Muara (R1M) tokoh Alif tetap berusaha untuk melakukan shalat tengah malam atau shalat tahajud di samping shalat wajib, dan ia merasakan kebesaran Tuhan dalam shalatnya. Hal ini terlihat dalam kutipan berikut. "Malam-malam aku bangun dan bersimpuh di sajadah minta kemudahan dalam hidup dan karierku". (hlm.71) 
Pada kutipan di atas, menandakan Alif melaksanakan perintah Allah dengan mengerjakan shalat dan mengamalkan perbuatan baik yang bernilai ibadah agar mendapat ridho dari Allah Swt yang kemudian memberikan ketenangan batin dalam dirinya. Shalat adalah bentuk peribadatan kepada Tuhan Yang Maha Esa. Melalui shalat kita akan membangun kedekatan dengan sang pencipta. Shalat merupakan bentuk ibadah yang paling utama dan merupakan esensi dari peng-abdian manusia kepada penciptanya. Dengan mengerjakan shalat secara tertib dan tepat waktu menandakan kepatuhan sekaligus kebaktian seorang hamba terhadap Tuhannya.

b. Wujud nilai religius hubungan manusia dengan manusia.

1) Meminta Perlindungan

Berikut ini adalah contoh kutipan yang termasuk ke dalam meminta perlindungan, hal tersebut dapat dibuktikan pada kutipan berikut. "Saya orangya," kataku dengan suara dimantap-mantapkan. Hatiku berdo'a untuk berlindung dari orang yang berniat jahat dan terkutuk". (hlm.36)

Pada kutipan di atas menunjukan bahwa termasuk dalam nilai religius yang ditunjukan pada kutipan "Hatiku berdo'a untuk berlindung dari orang yang berniat menjahati aku jahat dan terkutuk" memperlihatkan bahwa tindakan berdoa, berserah diri dan juga meminta perlindungan kepada Tuhan agar dijauhkan dari orang yang ingin berniat jahat dan mencelakai dirinya.

2) Berbakti kepada orang tua

Berikut ini adalah contoh kutipan yang termasuk ke dalam berbakti pada orang tua, hal tersebut dapat dibuktikan pada kutipan berikut. "Aku duduk bersimpuh di depan Amak dan tidak berani beringsur sampai mendengar jawabannya. Setelah be-berapa saat diam, Amak mengulang nasihatnya lagi, kemanapun dan apa-pun yang waang lakukan, selalu perbaharui niat, bahwa hidup singkat kita ini hanya karena Allah dan untuk membawa manfaat. Jangan ber-orientasi materi. Kalau memang sekolah jauh itu membawa manfaat dan waang niatkan sebagai ibadah, pailah. pergilah". (hlm.174)

Di dalam kutipan di atas terlihat bahwa nilai pendidikan religius dengan indikator ikhlas adalah nasihat dari Amak yang menyatakan bahwa hidup singkat ini hanya karena Allah. Oleh karena itu, pergunakanlah 
dengan jalan yang diridhoi-Nya dan mengamalkan segala perbuatan baik yang bernilai ibadah. Ikhlas berkaitan dengan tindakan dan perilaku seseorang yang dilakukan tanpa pamrih, hanya semata-mata mengharapkan keridhoan Allah.

3) Keakraban

Berikut ini adalah contoh kutipan yang termasuk ke dalam keakraban, hal tersebut dapat dibuktikan pada kutipan berikut. "Aku bersyukur sekali, kami berdua ternyata tidak hanya bisa menjadi pasangan hidup, tapi juga menjadi mitra kerja yang andal. Kami bagai dua elemen kimia yang jika digabungkan menjadi elemen baru yang kuat. Ketika seorang diri, kami hanya satu pribadi biasa, ketika bersatu, kami menjadi tim yang luar biasa. Kami saling melengkapi. Kami adalah satu". (hlm.313)

Kutipan di atas menunjukan bahwa menunjukan nilai religius yang melakukan sikap bersyukur karena sudah dipasangkan untuk berdua yang menjadikan sempurna. Ditunjukan pada kutipan "Kami bagai dua elemen kimia yang jika digabungkan menjadi elemen baru yang kuat. Ketika seorang diri, kami hanya satu pribadi biasa, ketika bersatu, kami menjadi tim yang luar biasa. Kami saling melengkapi. Kami adalah satu". Kutipan lainnya yang termasuk ke dalam keakraban, hal tersebut dapat dibuktikan pada kutipan berikut. "Menjelang pengujung Ramadan, aku diminta Ustad Fariz ikut mrnjadi juri lomba azan dan mengaji, serta pernah pula jadi imam salat Tarawih. Dinara dapat tugas menjadi pembaca acara Nuzulul Quran dan bersama ibu-ibu punya kesibukan sendiri mengatur penyaluran infak, menyiapkan buka bersama, dan lomba mengaji para ibu". (hlm.362)

Pada kutipan di atas termasuk ke dalam hubungan keakraban manusia dengan manusia. Alif Menjadi bagian memeriahkan ramadan sebagai juri lomba azan dan juga menjadi imam salat tarawih merupakan kebanggaan tersendiri. Dinara pun tidak mau kalah dengan mencari kesibukan sebagai pembaca acara di sebuah acara di penghujung ramadan yaitu nuzulul quran. Selain mengamalkan hal-hal yang baik kepada masyarakat tentunya Alif dan Dinara merupakan pasangan yang kompak dan akrab menciptakan hal-hal terbaru untuk dibagikan kepada orang lain. 


\section{4) Mendoakan orang lain}

Berikut ini adalah contoh kutipan yang termasuk ke dalam mendoakan orang lain, hal tersebut dapat dibuktikan pada kutipan berikut. "Selesai mengatupkan kedua tanganku di wajah sebagai penutup doa, aku ambil alquran kecilku di rak mushala. Hari Kamis malam Jumat biasanya jadwalku membaca yasin. Aku niatkan megirimi kebaikan bacaan mulia ini untuk almarhum Ayah dan keluargaku yang telah mendahului kami". (hlm.149)

Pada kutipan ini kebiasaan berdoa ditunjukkan oleh Alif setelah melakukan shalat dan membaca Alquran sehabis shalat kemudian mengirim doa kepada almarhum Ayah dan keluarga yang telah dahulu berpulang ke rahmatullah. Berdoa adalah memohon atau meminta sesuatu yang bersifat baik kepada Allah SWT agar diberikan kemudahan atau kelancaran dalam hidup. Berdoa memberikan gambaran bahwa seseorang sangat butuh bantuan dan pertolongan dari Sang Pencipta. Kutipan lainnya yang termasuk ke dalam mendoakan orang lain, hal tersebut dapat dibuktikan pada kutipan berikut."Aku bersimpuh lama-lama di sajadah. Doa utamaku tetap berharap akan ke-selamatan Mas Garuda. Tapi mungkin aku harus mulai berdamai dengan keadaan dan mendoakan akhir terbaik buatnya, hidup maupun mati. Bukan-kah semua yang hidup pasti berakhir dengan kematian. Hanya soal waktu saja. Kalaupun dia telah mati tidak dengan sia-sia. Mas Garuda yang se-lalu ringan tangan membantu orang lain. Semoga dia mendapatkan husnul khatimah, akhir yang baik". (hlm.356-357)

Pada kutipan diatas, Alif mendoakan Mas Garuda dan tetap berharap atas keselamatannya, dan Alif telah bisa meng-ikhlaskannya dengan bertawakal atau berserah diri sepenuhnya kepada Allah dalam menghadapi kesedihannya atas ke-hilangan Mas Garuda. Sesudah beragam usaha yang dilakukannya dengan pen-carian, dengan selalu berdoa, maka Alif menggantungkan semuanya kepada Allah agar ia bisa merelakan dengan perasaan yang ikhlas. Bertawakal merupakan berserah diri sepenuhnya kepada Allah dalam menghadapi, menanti atau menunggu hasil pekerjaan. Bertawakal juga penyerahan se-suatu kepada Allah atau mengantungkan urusan diri pada Allah. Tawakal adalah satu bentuk hubungan makhluk dengan Sang Khalik tawakal juga diartikan se-bagai pemasrahan diri secara total. Se-sudah beragam usaha dilakukan, dan ber- 
bagai doa dipanjatkan, maka yang terakhir adalah tawakal. Sikap tawakal menghindarkan seseorang dari sifat cemas, stress, dan sebagainya. Kutipan lainnya yang termasuk ke dalam mendoakan orang lain, hal tersebut dapat dibuktikan pada kutipan berikut.

“Ambo akan pulang ke kampung 2 x 11 Enang Lingkung, dekatdekat dengan Ibu. Kebelutan pula ambo sudah diminta oleh rektor Unand untuk jadi dosen. Begitu pula Uni Reza akan kembali ke almamaternya di IKIP. Tapi impian kami berdua itu ingin membuat sekolah SMA berasrama yang bagus. Terbagus di Sumatera Barat. Insa Allah". "Amin, amin," kata kami mendoakan. (hlm.365)

Pada kutipan di atas termasuk ke dalam hubungan mendoakan orang lain dari manusia dengan manusia. Suatu saat nanti Alif akan pulang dan mengabdi di salah satu perguruan tinggi yang ada di sumatera barat untuk menjadi dosen. Serta mempunyai keinginanyang sangat berkah sekali yaitu membuat sekolah menengah pertama paling bagus di sumatera barat. Hal hal tersebut seperti mengabdi dan juga keinginan yang sangat besar merupakan upaya yang semestinya di wujudkan dengan harapan serta kerja keras. Sebagai manusia juga kita wajib mendoakan hal-hal yang baik kepada orang lain agar menjadi suatu keberkahan yang berujung indah.

\section{c. Wujud nilai religius hubungan manusia dengan alam sekitar}

1) Memuji keindahan alam

Berikut ini adalah contoh kutipan yang termasuk ke dalam memuji keindahan alam, hal tersebut dapat dibuktikan pada kutipan berikut. “Masya Allah, indahnya!" teriak Dinara. Aku mengangguk mengiyakan sambil mataku mengeker dan sibuk menjepret foto sana-sini". (hlm.302)

Pada kutipan di atas menunjukan adanya nilai religius, hal itu dibuktikan dengan kutipan "Masya Allah, indahnya!". Hal tersebut menandakan keberkahan dengan artian bersyukur atas keindahan dan mengagumi apa yang telah Allah ciptakan di dunia ini, sehingga hal tersebut harus di syukuri dengan senang hati.

Nilai pendidikan karakter cinta tanah air yang terdapat dalam novel Rantau 1 Muara karya Ahmad Fuadi. Hasil analisis yang diperoleh berupa deskripsi mengenai nilai pendidikan karakter cinta tanah air pada novel Rantau 1 Muara. Berikut ini adalah hasil penelitian nilai-nilai 
pendidikan karakter pada novel Rantau 1 Muara karya Ahmad Fuadi, yang di dalamnya terdapat nilai pendidikan karakter kerjkeras yaitu:

2) Cinta Tanah Air

Cinta tanah air merupakan wujud yang timbul pada diri kita untuk mencintai negeri sendiri, sebuah perasaan mencintai dan menjaga oleh warga negara untuk negaranya dengan keinginan untuk rela mengabdi, berkorban, memelihara persatuan dan kesatuan, melindungi tanah airnya dari segala apapun yang menjatuhkan negaranya. Selain itu, cinta tanah air bisa diartikan perasaan yang muncul dengan rasa kebanggaan, rasa kecintaan, rasa memiliki, rasa menghargai, rasa menghormati, rasa kesetiaan dan kepatuhan yang dimiliki oleh setiap warga negara terhadap negaranya. Berikut ini merupakan kutipan nilai dari cinta tanah air yang terdapat dalam novel Rantau 1 Muara.

\section{d. Wujud nilai cinta tanah air hubungannya dengan diri sendiri \\ 1) Rasa nasionalis}

Berikut ini merupakan contoh kutipan yang mengandung wujud nilai kerja keras hubungan diri sendiri dengan kriteria rasa nasionalis adalah sebagai berikut. "Aku agak terganggu dengan komentarnya, yang pesimistis tentang Indonesia. Aku menyela, "jangan lupa, Indonesia sudah rindu ingin punya pemilu demokratis. Pemilu juli nanti pasti dibela dan dijaga semua orang. Saya tidak setuju dengan pendapat anda. Menurut saya, sebaliknya ini awal kebangkitan Indonesia. Mungkin dalam lima tahun sudah akan Smootsailing". (hlm.103)

Pada kutipan diatas terlihat pembelaan yang dilakukan oleh tokoh Alif terhadap tanah air dengan menyatakan tentang pendapat tidak setuju kepada wartawan bule berkaitan pandangannya terhadap kebangkitan era reformasi dan Alif berharap Indonesia akan bangkit menjadi negara yang Smootsailing. Alif menentang pandangan Statment yang meragukan negara Indonesia yang tidak akan berkembang dan bangkit. Hal tersebut merupakan cinta tanah air alif yang berhubungan dengan rasa nasionalis seperti dalam ajaran Islam jika sesuatu itu benar, maka bagaimanapun akan tetap dibela dan ditegakkan, "Sesungguhnya (Allah) yang mewajibkan atasmu (melaksanakan hukum-hukum) Al-Qur'an benar-benar akan mengembalikan kamu ke tempat kembali "(QS. Al Qashash: 85). Nasionalis suatu sikap dari masyarakat atau individu dalam merasakan adanya 
kesetiaan yang mendalam terhadap bangsa sendiri. Kutipan lain yang menandakan adanya sebuah nilai cinta tanah air adalah sebagai berikut. “Kan abang sendiri pernah bilang, sebaik-baiknya manusia itu yang bermanfaat bagi orang lain. Yang perlu manfaat itu ya Indonesia. Bangsa kita. "dia tiba-tiba jadi nasionalis tulen". (hlm.329)

Pada kutipan di atas merupakan sebuah nilai cinta tanah air, yang bagaimana hal tersebut dibuktikan pada kutipan “Sebaik-baiknya manusia itu yang bermanfaat bagi orang lain. Yang perlu manfaat itu ya Indonesia. Bangsa kita". Perkataan dari Dinara menegaskan bahwa dirinya cinta tanah air, memberitahukan suaminya Alif untuk memajukan bangsa Indonesia. Karena sebaik-baiknya manusia itu bermanfaat bagi orang lain. Sudah saatnya untuk memajukan Indonesia dengan sebuah karya-karya dan juga motivasi-motivasi agar bisa belajar di luar negeri dengan beasiswa, hal tersebut pastilah sangat membanggakan jika benar terjadi. Seperti ajaran Islam sebaik-baiknya manusia itu yang bermanfaat bagi orang lain, dan juga ada hadist "Sampaikan tentang Aku walaupun hanya satu ayat (Q. S HR. Bukhari)".

2) Rasa toleransi umat beragama

Berikut merupakan contoh kutipan yang mengandung wujud nilai cinta tanah air hubungan diri sendiri dengan kriteria rasa toleransi umat beragama adalah sebagai berikut. "Satu-satunya tempat yang nyaman dan tidak dipakai di hari jumat adalah sebuah ruangan bernama Miriam's Kitchen di basement. Ternyata pastor gereja ini mengizinkan kami memakai ruangan ini sebagai tempat salat Jumat. Kebetulan kami beberapa kali mengadakan kegiatan sosial bersama dengan pengurus gereja ini." (R1M: 210)

Pada kutipan di atas menjelaskan bahwa cinta tanah air dan juga menghargai keberagaman terlihat bahwa pastor gereja memberi izin ke mahasiswa Muslim yang ingin beribadah shalat Jumat, sebelumnya mahasiswa dan pastor telah telah menjalin hubungan yang baik dengan mengadakan kegiatan sosial bersama. Hal tersebut merupakan sikap menghargai keberagaman yang terjalin antara muslim dan non muslim. Hidup dalam negara yang penuh keragaman, baik dari suku, agama, maupun budaya. Untuk hidup damai dan berdampingan, tentu dibutuhkan toleransi satu sama lain. Menghargai keberagaman adalah 
perilaku terbuka dan menghargai segala perbedaan yang ada dengan sesama. Biasanya orang yang bertoleransi terhadap perbedaan kebudayaan dan agama adalah orang yang menghargai keberagaman. Hal tersebut dikuatkan dengan kutipan "Ternyata pastor gereja ini mengizinkan kami memakai ruangan ini sebagai tempat salat Jumat. Kebetulan kami beberapa kali mengadakan kegiatan sosial bersama dengan pengurus gereja ini". Menghargai keberagaman juga berarti menghormati dan belajar dari orang lain, menghargai perbedaan sehingga tercapai kesamaan sikap dan toleransi terhadap umat beragama. Contohnya adalah toleransi beragama, dimana penganut mayoritas dalam suatu masyarakat mengizinkan keberadaan agama lainnya. Seperti dalam hadist ajaran Islam "Bagi orang-orang yang berbuat baik, ada pahala yang terbaik (surga) dan tambahannya. Dan muka mereka tidak ditutupi debu hitam dan tidak (pula) kehinaan. Mereka itulah penghuni surga, mereka kekal di dalamnya"(Yûnus/10:26).

\section{Simpulan}

Nilai pendidikan karakter religius. Pada novel Rantau 1 Muara karya Ahmad Fuadi, dapat diketahui bahwa nilai karakter religius dan cinta tanah air yang terdapat dalam keseluruhan isi novel. Namun dari kedua nilai religius dan cinta tanah air yang paling mendominasi adalah nilai religius. Pada nilai-nilai pendidikan karakter yang terdapat pada novel Rantau 1 Muara ini menggambarkan kepada kita semua bagaimana manusia harus bersikap dan bertindak dalam menjalani kehidupan sesuai nilai yang kita dapatkan. Dari karakter religius yang terdapat pada novel Rantau 1 Muara karya Ahmad Fuadi ini terbagi meliputi wujud religius hubungan manusia dengan tuhan diantaranya beribadah, mengucap salam, berdoa, bersyukur dan mohon ampun. Wujud religius hubungan manusia dengan manusia diantaranya meminta perlindungan, berbakti kepada orang tua, keakraban, dan mendiakan orang lain. Selanjutnya wujud religius hubungan manusia dengan alam yaitu memuji keindahan alam. Sedangkan nilai pendidikan karakter cinta tanah air meliputi wujud nilai cinta tanah air hubungannya dengan diri sendiri yaitu rasa nasionalis dan rasa toleransi antara umat beragama.

Berdasarkan nilai pendidikan karakter religius tersebut wujud terbagi menjadi 17 frekuensi dari nilai religius sedangkan nilai cinta tanah air terbagi menjadi 3 frekuensi. Oleh karenai itu, harus ada keterkaitan 
antara satu dan yang lainnya. Setiap manusia harus memiliki sebuah nilainilai pendidikan karakter religius dan cinta tanah air yang dapat dijadikan pedoman didalam hidupnya agar rasa yang ada di dalam diri bisa seimbang serta diajarkan dalam kehidupan sehari-hari. Berdasarkan hasil analisis, diri manusia memiliki nilai-nilai pendidikan karakter religius dan cinta tanah air yang dapat ditemui dalam kehidupan sehari-hari. Penelitian ini penting untuk diketahui oleh masyarakat karena bisa mengambil contoh-contoh yang bermanfaat dari novel Rantau 1 Muara baik itu nilai religius dan juga cinta tanah air yang nantinya dapat diaplikasikan dalam kehidupan yang menjadi lebih baik[.]

\section{REFERENSI}

Abourjilie, C. Character Education. North Carolina: Department of Public Instruction, 2002.

Beachum, F. "Pre-service Teachers' Perceptions of Character Education." MidWestern Educational Researcher 18, no. 4 (2005): 45-50.

Beachum, F. D, Mccray, C. R, Yawn, C. D, dan Obiakor, F. E. “Support and importance of character education: pre-service teacher perceptions." Education 133, no. 4 (2013): 470-80.

Berkowitz, Marvin W., dan John H. Grych. "Fostering Goodness: Teaching Parents to Facilitate Children's Moral Development." Journal of Moral Education 27, no. 3 (September 1998): 371-91. https://doi. org/10.1080/0305724980270307.

Bohlin, Karen E., Deborah Lynn Farmer, Kevin Ryan, dan Kevin Ryan. Building character in schools resource guide. 1st ed. The Jossey-Bass education series. San Francisco: Jossey-Bass, 2001.

Brannon, Diana. "Character Education: It's a Joint Responsibility." Kappa Delta Pi Record 44, no. 2 (Januari 2008): 62-65. https:/ / doi.org/10.10 80/00228958.2008.10516496.

Creswel, J. W. Research design: pendekatan kualitatif, kuantitatif, dan mixed. Yogyakarta: PT Pustaka Pelajar, 2010. 
Demirel, M. "Self-efficacy beliefs of elementary teachers and school principals for character education." Hacettepe University Journal of Education 37 (2009): 36-49.

Fuadi, A. Rantau 1 Muara. Jakarta: Gramedia Pustaka Utama Gramedia Widiasarana Indonesia, 2013.

Healea, Christopher Daryl. "Character Education with Resident Assistants: A Model for Developing Character on College Campuses." Journal of Education 186, no. 1 (Januari 2006): 65-77. https://doi. org/10.1177/002205740618600107.

Istyarini, Rafika Bayu Kusumandari. “Character Education Development Model-Based E-Learning and Multiple in Telegency in Childhood in Central Java." Global Journal of Computer Science and Technology: H Information \& Technology 15, no. 3 (2015): 12.

Kemendiknas. Pengembangan Pendidikan Budaya dan Karakter Bangsa. Jakarta: Badan Penelitian dan Pengembangan Kurikulum, 2010.

Khan, Yahya. Penilaian Pembelajaran Bahasa. Yogyakarta: BPFE - Yogyakarta, 2010.

Komalasari, Kokom, dan Didin Saripudin. “The Influence of Living Values Education-Based Civic Education Textbook on Student's Character Formation." International Journal of Instruction 11, no. 1 (25 Januari 2018): 395-410. https:// doi.org/10.12973/iji.2018.11127a.

Lapsley, D. K., dan Narvaez, D. “Character Education. In K. A. Renninger \& I. E. Sigel (Eds), Handbook of Child Psychology." Child Psychology in Practice 4 (2006): 248-96.

Ledford, Alice T. "Professional Development for Character Education: An Evaluation of Teachers' Sense of Efficacy for Character Education." Scholar-Practitioner Quarterly 5, no. 3 (t.t.): 256-73.

Lickona, T. Educating for character. New York, NY: Bantam Books, 1991.

- - - Educating for character. Mendidik untuk Membentuk Karakter.Terj. Juma Wadu Wamaungu. Jakarta: Bumi Aksara, 2016.

Lickona, T, Schaps, E, dan Lewis, C. CEP's Eleven Principles of Effective Character Education. Washington, DC: Character Education Partnership, 2003. 
Lickona, Thomas. "The Return of Character Education" 51, no. 3 (1993): 6-11.

Lickona, Tom, Eric Schaps, dan Catherine Lewis. "Of Effective Character EducationTM." Character Education Partnership, 2002, 25-34.

Maryati, Iyam, dan Nanang Priatna. "Integration of Values Mathematics Characters through Contextual Learning (Literatur Study)." 4th ICRIEMS Proceedings Published by The Faculty Of Mathematics And Natural Sciences Yogyakarta State University, 2017, 41-49.

Muslich, Masnur. Pendidikan karakter: menjawab tantangan krisis multidimensional. Cet. 1. Jakarta: Bumi Aksara, 2011.

Nucci, L, Drill, K, Larson, C, dan Browne, C. "Preparing preservice teachers for character education in urban elementary schools." Journal of Research in Character Education 3, no. 81-96 (2005).

Nurfalah, Farida, dan Indah Kurniawati. “Character Education Communication Model Nation to Form the Integrity of Self in Students." Journal of Humanities and Social Sciences (AHJSS) 3, no. 1 (2015): 151-62.

Peterson, Christopher, dan Martin E. P. Seligman. Character Strengths and Virtues: A Handbook and Classification. Washington, DC : New York: American Psychological Association; Oxford University Press, 2004.

Philips, Simon. Refleksi Karakter Bangsa. Jakarta: Forum Kajian Antroplogi Indonesia, 2008.

Revell, Lynn, dan James Arthur. "Character Education in Schools and the Education of Teachers." Journal of Moral Education 36, no. 1 (Maret 2007): 79-92. https:/ / doi.org/10.1080/03057240701194738.

Romanowski, M. H. "Through the Eyes of Teachers: High School Teachers' Experiences with Character Education." American Secondary Education 34, no. 1 (2005): 6-23.

Rusydiyah, Evi Fatimatur. "Character Education Through the Constructivist Design of Islamic Education Subject at Elementary School Pembangunan Jaya II in Gedangan Sidoarjo." AL-Ta Lim 21, no. 3 (30 November 2014): 227-38. https://doi.org/10.15548/ jt.v21i3.108. 
Sanderse, Wouter. "The Meaning of Role Modelling in Moral and Character Education." Journal of Moral Education 42, no. 1 (Maret 2013): 28-42. https://doi.org/10.1080/03057240.2012.690727.

Sarros, James C., Brian K. Cooper, dan Anne M. Hartican. "Leadership and Character." Leadership \& Organization Development Journal 27, no. 8 (Desember 2006): 682-99. https://doi. org/10.1108/01437730610709291.

Schaps, E, dan Lewis,C. "Perils on an essential journey: Building school community." Phi Delta Kappan 81, no. 3 (1999): 215-18.

Segara, I Nyoman Yoga. "Character Education trough Disposition Growth, Love of the Homeand and Inclusive Life Attitude." Dharma Acarya Faculty International Seminar (DAFIS) 1 (2016): 24-31.

Stiff-Williams, Helen R. "Widening the Lens to Teach Character Education Alongside Standards Curriculum." The Clearing House: A Journal of Educational Strategies, Issues and Ideas 83, no. 4 (24 Mei 2010): 115-20. https://doi.org/10.1080/00098651003653030.

Sugiyono. Metode Penelitian Pendidikan Pendekatan Kuantitatif, Kualitatif, dan RED. Bandung: Alfabeta, 2014.

Sunarti, Euis. Menggali Kekuatan Cerita. Jakarta: PT Elek Media Komputindo, 2005.

Tillman, D. Living values: Avtivities for children ages 8-14. Jakarta: PT Gramedia Widiasarana Indonesia, 2004.

Wibowo, Agus. Pendidikan karakter: strategi membangun karakter bangsa berperadaban. Cet. 1. Yogyakarta: Pustaka Pelajar, 2012. 